\title{
Correction: Association Between Usage of an App to Redeem Prescribed Food Benefits and Redemption Behaviors Among the Special Supplemental Nutrition Program for Women, Infants, and Children Participants: Cross-Sectional Study
}

Qi Zhang ${ }^{1}$, PhD; Junzhou Zhang ${ }^{2}$, PhD; Kayoung Park ${ }^{3}$, PhD; Chuanyi Tang ${ }^{4}, \mathrm{PhD}$

\footnotetext{
${ }^{1}$ School of Community and Environmental Health, Old Dominion University, Norfolk, VA, United States

${ }^{2}$ Department of Marketing, Feliciano School of Business, Montclair State University, Montclair, NJ, United States

${ }^{3}$ Department of Mathematics and Statistics, Old Dominion University, Norfolk, VA, United States

${ }^{4}$ Department of Marketing, Old Dominion University, Norfolk, VA, United States
}

\section{Corresponding Author:}

Qi Zhang, PhD

School of Community and Environmental Health

Old Dominion University

3130 Health Sciences Building

Old Dominion University

Norfolk, VA, 23529

United States

Phone: 17576836870

Email: qzhang@odu.edu

\section{Related Article:}

Correction of: https://mhealth.jmir.org/2020/10/e20720/

(JMIR Mhealth Uhealth 2020;8(10):e25073) doi: 10.2196/25073

In "Association Between Usage of an App to Redeem Prescribed Food Benefits and Redemption Behaviors Among the Special Supplemental Nutrition Program for Women, Infants, and Children Participants: Cross-Sectional Study" (JMIR Mhealth Uhealth 2020;8(10):e20720) the authors noted one error.

In the reference list, the author of Reference 22 was incorrectly listed as "Juvenile Products Manufacturers Association". The correct author is "JPMA, Inc", an unrelated organization.
The correction will appear in the online version of the paper on the JMIR Publications website on October 21, 2020, together with the publication of this correction notice. Because this was made after submission to PubMed, PubMed Central, and other full-text repositories, the corrected article has also been resubmitted to those repositories.

\section{Reference}

22. JPMA, Inc. WICShopper: the mobile app for WIC participants. WICShopper. URL: https://ebtshopper.com/ [accessed 2020-04-12]

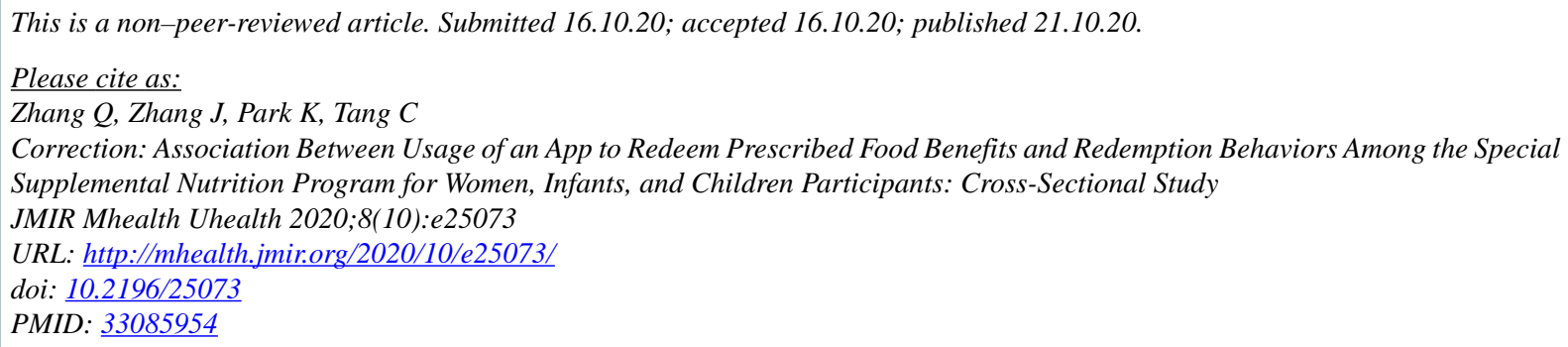


(C)i Zhang, Junzhou Zhang, Kayoung Park, Chuanyi Tang. Originally published in JMIR mHealth and uHealth (http://mhealth.jmir.org), 21.10.2020. This is an open-access article distributed under the terms of the Creative Commons Attribution License (https://creativecommons.org/licenses/by/4.0/), which permits unrestricted use, distribution, and reproduction in any medium, provided the original work, first published in JMIR mHealth and uHealth, is properly cited. The complete bibliographic information, a link to the original publication on http://mhealth.jmir.org/, as well as this copyright and license information must be included. 